\title{
Wastewater Valorization by Pure Bacterial Cultures to Extracellular Polymeric Substances (EPS) with High Emulsifying Potential and Flocculation Activities
}

\author{
Efi-Maria Drakou ${ }^{1}$ Catarina L. Amorim ${ }^{2,3}$ • Paula M. L. Castro ${ }^{2}$ • \\ Fostira Panagiotou $^{1} \cdot$ Ioannis Vyrides $^{1} \mathbb{B}$
}

Received: 27 October 2016 / Accepted: 6 July 2017 / Published online: 11 July 2017

(C) Springer Science+Business Media B.V. 2017

\begin{abstract}
Nowadays much effort has been devoted for the development of cost-effective and environmentally friendly processes to obtain extracellular polymeric substances (EPS) with high emulsifying and flocculation activities. The aim of this study was to evaluate the capacity of bacterial strains previously isolated from oil-contaminated areas to produce EPS with high emulsification and bioflocculant properties during cultivation in domestic and bilge wastewater and in industrial crude glycerol. A total of seven bacterial strains were screened for EPS production, from which two strains, Pseudomonas aeruginosa LVD-10 and Enterobacter sp. SW, were selected as potential EPS producers. EPS with high emulsifying capacity in olive oil (a maximum of 96.6 and $89.8 \%$ for strain SW and LVD-10, respectively) was produced using bilge wastewater as substrate. EPS with a slightly lower emulsifying capacity was obtained using crude glycerol. In addition, the flocculation activity of the EPS extracted from strains LVD-10 and SW grown on crude glycerol was considerably higher (81.6 and $73.3 \%$, respectively) than that obtained with other substrates. This is the first study that points out that EPS with
\end{abstract}

Ioannis Vyrides

ioannis.vyrides@cut.ac.cy

1 Faculty of Geotechnical Sciences and Environmental Management, Department of Environmental Science and Technology, Cyprus University of Technology, 30 Archbishop Kyprianos Str., 3036 Limassol, Cyprus

2 Universidade Católica Portuguesa, CBQF - Centro de Biotecnologia e Química Fina - Laboratório Associado, Escola Superior de Biotecnologia, Rua Arquiteto Lobão Vital, Apartado 2511, 4202-401 Porto, Portugal

3 Biology Department and CESAM, University of Aveiro, Campus Universitário de Santiago, 3810-193 Aveiro, Portugal emulsifying and flocculation potential activity can be produced from bilge wastewater and crude glycerol. The production of biopolymers with broad biotechnological applications using low-cost substrates can be a means to valorise waste streams.

Keywords Extracellular polymeric substances . Biovalorization · Emulsification · Flocculation activity

\section{Introduction}

Extracellular polymeric substances (EPS) are a diverse class of macromolecules consisting of proteins, carbohydrates, nucleic acids, lipids and other compounds. EPS produced by microorganisms, known as biopolymers, are very attractive for the industrial sector, representing a potential alternative to conventional chemical polymers production because of their ease of biodegradation, high efficiency and non-toxic properties $[1,2]$. Also, the production of microbial-derived EPS could represent a way to obtain these biomolecules through a more sustainable process. The interest on EPS for different biotechnology applications has been growing. Recently, EPS have been recognised as potential emulsifiers with applicability in various fields, such as microbial oil recovery, pharmacology or food additives $[2,3]$. In addition, EPS can be used as bioflocculants, which is especially important for its industrial application in the removal of metal ions and dyes in downstream processing and in processing of food and chemicals, and for sludge dewatering [4]. Moreover, produced waste is posing a global challenge regarding its managing, disposal and treatment. The current environmental policies encourage waste valorization, looking at the waste as a possible resource to be used for other purposes. Nevertheless, one 
of the main factors limiting the synthesis of bacterial EPS is the high cost of production, in part due to the cost of purchasing the raw substrate [2]. The use of waste streams could reduce the cost of biopolymer production and thus improve the process economics. Therefore, research on the biovalorization of waste streams through the production of valuable compounds (e.g. EPS polymers) is timely. To date, studies mainly report on the optimisation of the yield production of the EPS using easily degradable carbon sources (e.g. glucose or maltose) as substrate. Only a few studies on the EPS production using low-cost substrates based on industrial or domestic waste streams can be found in the literature. Recently, Nurul Adela et al. [5] used palm oil effluent as carbon source, obtaining a maximum concentration of $6.4 \mathrm{~g} / \mathrm{L}$ of EPS using Bacillus marisflavi NA8 (Table 1). The maximum bioflocculant production was achieved at an early stationary phase and the EPS flocculation activity reached $80 \%$. Furthermore, Bezawada et al. [6] and More et al. [1] evaluated the production of EPS with flocculation ability by Serratia sp. 1, both using sterile wastewater sludge as substrate. Bezawada et al. [6] found that the production of EPS could reach $2.45 \mathrm{~g} / \mathrm{L}$ (at the end of $48 \mathrm{~h}$ ) with a maximum flocculation activity of 76.4\%. Similar results were reported by More et al. [1], where $2.3 \mathrm{~g} / \mathrm{L}$ of EPS (after $72 \mathrm{~h}$ ) with a maximum flocculation activity of $79.1 \%$ was obtained when autoclaved wastewater sludge was used as substrate (Table 1). Gupta et al. [7] also reported EPS production (Table 1) when 50\% of sterilised wastewater was used as a substrate by Bacillus sp. ISTVK1. A higher EPS production $(2.58 \mathrm{~g} / \mathrm{L})$ was obtained when dairy wastewater was used as feedstock by Klebsiella mobilis [8] (Table 1). Moreover, in this case, the produced EPS had an incredibly high flocculation activity (ca. 95.4\%). On the other hand, Calvo et al. [9] reported a lower EPS synthesis (0.47-0.94 g/L) by Ochrobactrum anthropic $\mathrm{AD} 2$, when using a more complex wastewater consisting of glucose-containing nutrient broth medium amended with different petroleum hydrocarbons.
Interestingly, the emulsification activity of the produced EPS depended on the type of hydrocarbon present on the media and, EPS with a maximum emulsification activity of 95.1\% was produced when the nutrient broth was amended with octane. However, with real petroleum refinery wastewater, Ramasamy et al. [10] reported that Ochrobactrum anthropi MP3 could produce EPS with a yield of about $0.42 \mathrm{~g} / \mathrm{L}$ and an emulsification activity of $60 \%$ in diesel.

In this study the potential of waste streams biovalorization was explored using newly isolated microorganisms aiming at the production of EPS suitable for biotechnological applications and the simultaneous degradation of those substrates. To our knowledge, low-cost substrates such as domestic wastewater, bilge wastewater and crude glycerol have not been used as feedstock for EPS generation. In this way, this study aimed to highlight the potential of valorizing those types of wastewater through the synthesis of added value products whilst treating those waste streams.

\section{Materials and Methods}

\section{Microorganisms Selection}

Seven bacterial strains previously isolated from oil-contaminated sites and characterised by $16 \mathrm{~S}$ rRNA [11] were screened for EPS production. The tested bacterial strains were Pseudomonas aeruginosa LVD-10, Enterobacter sp. LA9, Pseudomonas aeruginosa XP7, Enterobacter sp. SW, Citrobacter sp. D2, Bacillus sp. KSA and Enterobacter sp. D1. In addition, two bacterial strains known as high EPS producers, namely Pseudomonas fluorescens (DSM 50090) [12] and Rhodococcus ruber (DSM 43338) [13], supplied by DSMZ, Germany, were included as reference strains for comparison. A pre-screening qualitative method for the selection of potential EPS producers was carried out according to Subramanian et al. [14]. Briefly, strikes of pure cultures were carried out onto Plate Count

Table 1 Other studies that used wastewater as a substrate for bacterial EPS production

\begin{tabular}{|c|c|c|c|c|}
\hline Microorganism & Substrate & Type of EPS, EA or FA & EPS production (g/L) & References \\
\hline Serratia sp.1 (EU031758) & $\begin{array}{l}\text { Sterilised wastewater sludge ( } 20 \mathrm{~g} \\
\text { of suspended solids } / \mathrm{L})\end{array}$ & $\mathrm{FA}=76.4 \%$ & $\begin{array}{l}2.45 \mathrm{~g}_{\mathrm{LB}-\mathrm{EPS}} / \mathrm{L} \text { and } \\
0.99 \mathrm{~g}_{\mathrm{TB}-\mathrm{EPS}} / \mathrm{L}\end{array}$ & [6] \\
\hline Ochrobactrum anthropi AD2 & $\begin{array}{l}\text { Glucose nutrient broth media amended with vari- } \\
\text { ous hydrocarbons (n-octane, mineral light and } \\
\text { heavy oils and crude oils) }\end{array}$ & $\begin{array}{l}\text { FA }=95.1 \% \text { (media } \\
\text { amended with } \\
\text { n-octane) }\end{array}$ & $0.470-0.940 \mathrm{~g} / \mathrm{L}$ & [9] \\
\hline Bacillus sp. ISTVKI & $\begin{array}{l}50 \% \text { of filtered sterile municipal wastewater with } \\
0.5 \% \mathrm{w} / \mathrm{v} \text { sucrose }\end{array}$ & Not reported & $0.7 \mathrm{~g} / \mathrm{L}$ & [7] \\
\hline Bacillus marisflavi NA & Palm oil mill effluent & $\mathrm{FA}=80 \%$ & $6.4 \mathrm{~g} / \mathrm{L}$ & [5] \\
\hline Ochrobactrum anthropic MP3 & Petroleum refinery wastewater & $\mathrm{EI}=60 \%$ & $0.42 \mathrm{~g} / \mathrm{L}$ & {$[10]$} \\
\hline Klebsiella mobilis & Dairy wastewater & $\mathrm{FA}=95.4 \%$ & $2.58 \mathrm{~g} / \mathrm{L}$ & [8] \\
\hline
\end{tabular}

$F A$ flocculation activity, $E A$ emulsification activity 
Agar (PCA) and Sabouraud's dextrose agar (SDA) media. The plates were incubated at $30^{\circ} \mathrm{C}$ for $48 \mathrm{~h}$ and the EPS producing microorganisms selected based on the formation of mucoidal colonies (which displayed viscous or sticky growth due to production of large quantities of EPS) on the growth medium and on the string forming ability by touching it with an inoculating loop.

\section{EPS Production}

\section{EPS Production Using Synthetic Mineral Salt Medium Containing Glucose as Substrate}

The strains grown on PCA plates (incubated for $24 \mathrm{~h}$ at $30^{\circ} \mathrm{C}$ ) were used to inoculate $100 \mathrm{~mL}$ of growth medium $(5 \mathrm{~g} / \mathrm{L}$ tryptone, $2.5 \mathrm{~g} / \mathrm{L}$ yeast extract and $1 \mathrm{~g} / \mathrm{L}$ glucose). The inoculated flasks were then incubated at $30^{\circ} \mathrm{C}$ and $100 \mathrm{rpm}$ for $24 \mathrm{~h}$. The cells were harvested by centrifugation at $6000 \mathrm{rpm}$ for $20 \mathrm{~min}$, washed and re-suspended in growth medium. Then, $28 \mathrm{~mL}$ of the growth medium were inoculated in $1 \mathrm{~L}$ flasks containing $400 \mathrm{~mL}$ of mineral salt medium $\left(25 \mathrm{~g} / \mathrm{L}\right.$ glucose, $0.2 \mathrm{~g} / \mathrm{L} \mathrm{MgSO}_{4} .7 \mathrm{H} 2 \mathrm{O}, 2 \mathrm{~g} / \mathrm{L}$ $\mathrm{K}_{2} \mathrm{HPO}_{4}, 1 \mathrm{~g} / \mathrm{L} \mathrm{KH}_{2} \mathrm{PO}_{4}, \mathrm{~g} / \mathrm{L} \mathrm{NH}_{4} \mathrm{Cl}$ and $0.01 \mathrm{~g} / \mathrm{L}$ yeast extract). Glucose and $\mathrm{MgSO}_{4}$ were prepared and sterilised separately and then mixed aseptically with the other reagents before the inoculation, as referred in Subramanian et al. [13]. The $\mathrm{pH}$ was adjusted to 7.0. The liquid cultures were incubated at $30^{\circ} \mathrm{C}$ with constant shaking $(100 \mathrm{rpm})$ for $72 \mathrm{~h}$.

\section{EPS Production Using Wastewater as Substrate}

The strains that produced the highest EPS concentration in synthetic mineral salt medium containing glucose were compared to the reference strains (Pseudomonas fluorescens (DSM 50090) and Rhodococcus ruber (DSM 43338)) and selected for further experiments in different types of wastewater namely, undiluted domestic wastewater (DWW), undiluted bilge wastewater (BWW) and 4.5\% v/v of crude glycerol. DWW was collected from Moni Municipal Wastewater Treatment Plant (Limassol) and BWW from the Ecofuel Ltd (Cyprus). Bilge is considered a recalcitrant wastewater which generally includes in its composition lubricating oil, cleaning diesel oil, oily sludge, spills from the engine room, water leaks from internal pipes, and seawater [15]. The crude glycerol was collected from a biodiesel manufacturing company (Biodiesel Cyprus Ltd) in Cyprus and used in its raw form without any pre-treatment.

Experiments were run in $500 \mathrm{~mL}$ flasks containing 100 $\mathrm{mL}$ of wastewater. The $\mathrm{pH}$ was adjusted to $\mathrm{pH} 7.0$ followed by sterilization at $121^{\circ} \mathrm{C}$ for $30 \mathrm{~min}$. The selected strains grown in growth media were then inoculated $(3 \% v / v)$ in the filtered $(0.45 \mu \mathrm{m})$ wastewater. For the EPS production using crude glycerol, $4.5 \% \mathrm{v} / \mathrm{v}$ of this substrate was used as sole carbon source. After inoculation, all the flasks were incubated at $30^{\circ} \mathrm{C}$ and $100 \mathrm{rpm}$ for assessing EPS production. For each assay experiments were performed in duplicate under sterile conditions.

The cultures in DWW were incubated for 3 days whereas those in BWW and crude glycerol were incubated longer (10 days) due to the high organic content of these substrates.

The composition of the wastewater used was evaluated before and after treatment with the bacterial strains. Chemical oxygen demand (COD) was determined according to standard methods [16]. The determination of wastewater's phosphate, ammonium, nitrite and nitrate content was performed using photometric test kits (Spectroquant ${ }^{\circledR}$, Merck Millipore), according to the manufacturer's instructions.

\section{EPS Extraction}

EPS extraction was carried out according to Bezawada et al. [6] with some modifications. Samples $(30 \mathrm{~mL})$ were collected from the liquid cultures at different time points $(24,48$ and $72 \mathrm{~h})$ and then centrifuged at $6000 \mathrm{rpm}, 4^{\circ} \mathrm{C}$ for $20 \mathrm{~min}$. The supernatant, which contained loosely bound extracellular polysaccharides (LB-EPS), was mixed with 95\% of ethanol in 1:1 ratio and kept overnight at $-20^{\circ} \mathrm{C}$ for EPS precipitation. The pellet, which contained tightly bound extracellular polysaccharides (TB-EPS) was re-suspended in deionised water to the initial volume (30 $\mathrm{mL}$ ) and heated at $65^{\circ} \mathrm{C}$ for $30 \mathrm{~min}$ in a water-bath. Then, the samples were centrifuged at $6000 \mathrm{rpm}$ for $20 \mathrm{~min}$ and the supernatant containing the released TB-EPS was mixed with ethanol in the same way as described for LB-EPS. After the overnight precipitation, TB-EPS was collected by centrifugation at $6000 \mathrm{rpm}, 4^{\circ} \mathrm{C}$ and $45 \mathrm{~min}$.

\section{EPS Dry Weight}

The extracted EPS was filtered with GF/C filters (Whatman glass microfiber filters, $47 \mathrm{~mm}$ diameter) and the filters were placed overnight in the oven at $105^{\circ} \mathrm{C}$. The dry weight of the extracted EPS (LB and TB) was calculated by the difference in the mass of the filter before and after filtration.

\section{EPS Emulsification Activity}

The emulsification activity of the extracted EPS was determined according to Cooper and Goldenberg [17]. Samples were taken at three time points 24,48 and $72 \mathrm{~h}$. The extracted LB- and TB-EPS ( $4 \mathrm{~mL}$ of each) were transferred to glass test tubes containing $4 \mathrm{~mL}$ of olive oil or diesel. The two phases were mixed at high speed 
vortex, for $1 \mathrm{~min}$ and left to stand for $24 \mathrm{~h}$ at room temperature. The emulsification activity (EA) was determined according to the following Eq. (1):

$E A(\%)=\frac{\text { Height of emulsion layer }(\mathrm{cm})}{\text { Total height of the mixture }(\mathrm{cm})} \times 100$

\section{EPS Flocculation Activity}

The flocculating activity (FA) was measured using kaolin suspensions (5 g/L Kaolin clay) as described by Sathiyanarayanan [18]. For that, $1 \% w / v$ of $\mathrm{CaCl}_{2}$ and $0.1 \mathrm{~mL}$ of extracted EPS were added to $50 \mathrm{~mL}$ of kaolin suspension, mixed by vortexing for $1 \mathrm{~min}$ and then allowed to stand for $5 \mathrm{~min}$ at room temperature. Finally, the optical density at $550 \mathrm{~nm}\left(\mathrm{OD}_{550 \mathrm{~nm}}\right)$ of the aqueous phase was measured with an UV/Vis spectrophotometer. A control was prepared in the same way but deionised water was used instead of extracted EPS. FA was estimated according to the following Eq. (2):

$F A(\%)=\frac{(B-A)}{B} \times 100$,

where A is the optical density of samples containing EPS and $\mathrm{B}$ is the optical density of the control.

\section{Results and Discussion}

\section{Selection of EPS Producing Bacterial Strains}

From the 7 bacterial strains examined, all formed mucoid and sticky colonies in Plate count agar medium and Sabouraud's dextrose agar, indicating their ability for EPS production. The EPS production was then evaluated in liquid cultures using growth medium containing glucose $(25 \mathrm{~g} / \mathrm{L})$ as the sole carbon source to select the most promising strains. Out of the seven tested strains, Pseudomonas aeruginosa LVD-10 and Enterobacter sp. SW achieved the highest production of EPS (50 and $67 \mathrm{mg}_{\text {total EPS }} / \mathrm{L}$, respectively) (data not shown) after $48 \mathrm{~h}$. Interestingly the produced EPS concentration by Enterobacter sp. SW was slightly higher than that obtained by the reference strain Rhodococcous ruber. Nevertheless, the highest EPS production was achieved by the other reference strain Pseudomonas fluorescence $\left(136 \mathrm{mg}_{\text {total EPS }} / \mathrm{L}\right)$ (data not shown). From the isolated strains, Pseudomonas aeruginosa LVD-10 and Enterobacter sp. SW were the most promising strains for EPS production, therefore further experiments were conducted with these two bacterial strains.

\section{EPS Production Using Wastewater as a Substrate}

Three types of wastewater including DWW, BWW and crude glycerol were used as substrate for EPS production. The initial DWW contained $266 \mathrm{mg} / \mathrm{L}$ of COD, $2.42 \mathrm{mg} / \mathrm{L}$ of $\mathrm{NH}_{4}^{+}, 2.93 \mathrm{mg} / \mathrm{L}$ of $\mathrm{PO}_{4}^{-}, 0.28 \mathrm{mg} / \mathrm{L} \mathrm{NO}_{2}^{-}$and $0.85 \mathrm{mg} / \mathrm{L} \mathrm{NO}_{3}^{-}$, whereas BWW consisted of $7800 \mathrm{mg} / \mathrm{L}$ of COD, $0.6 \mathrm{mg} / \mathrm{L}$ of $\mathrm{NH}_{4}{ }^{+}$and $54.2 \mathrm{mg} / \mathrm{L}$ of $\mathrm{PO}_{4}^{-}$. The crude glycerol consisted of $541 \mathrm{~g} / \mathrm{L}$ glycerol, $192 \mathrm{~g} / \mathrm{L}$ methanol, $8.25 \% \mathrm{w} / \mathrm{v}$ ash content, $0.1 \% \mathrm{w} / \mathrm{v}$ water content and $37.63 \% w / v$ MONG (matter organic non-glycerol). COD removal by $P$. aeruginosa LVD-10 and Enterobacter sp. SW in each type of wastewater. The low initial organic content present in DWW in comparison with the other used substrates could be the reason for the highest COD removal obtained for this type of wastewater (Fig. 1). The COD was reduced rapidly, with $95 \%$ and $97 \%$ of removal after $72 \mathrm{~h}$ of cultivation with SW and LVD-10, respectively. For BWW, on the other hand, at the end of 10 days of treatment, a lower percentage of 62 and $51 \%$ of COD removal was achieved by $P$. aeruginosa LVD-10 and Enterobacter sp. $\mathrm{SW}$, respectively. In addition to its higher initial COD concentration $(8600 \mathrm{mg} / \mathrm{L}), \mathrm{BWW}$ in general has in its composition several recalcitrant compounds which can inhibit the bacterial metabolism; thus a longer time was needed to remove the COD content present in BWW. After 10 days of incubation, the COD removal for diluted crude glycerol (initial COD of $10000 \mathrm{mg} / \mathrm{L}$ ) was of 76 and $82 \%$ for Enterobacter sp. SW and P. aeruginosa LVD-10, respectively (Fig. 1). In general, the toxic and recalcitrant compounds present in crude glycerol are organic impurities present at low concentrations when compared with methanol,

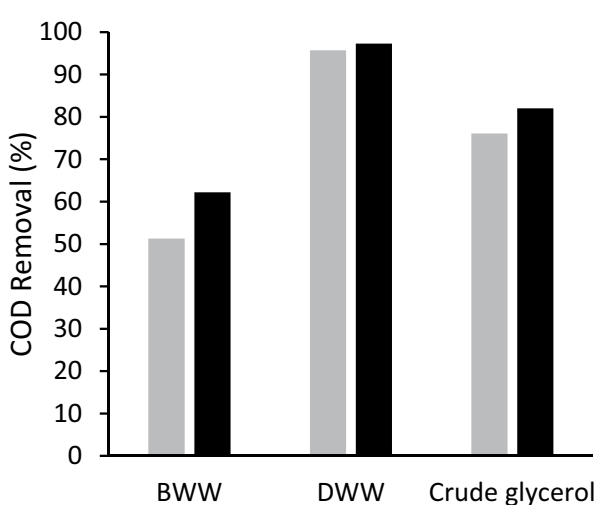

Fig. 1 COD removal (\%) by Enterobacter sp. SW (grey bars) and $P$. aeruginosa LVD-10 (black bars) when cultivated in bilge wastewater (BWW), domestic wastewater (DWW) and $4.5 \%$ of crude glycerol. For BWW and crude glycerol, COD removal by each bacterial strain was examined at day-10 and for DWW at day-3 of incubation and expressed as percentage of the initial amount of COD present in each type of wastewater. Values are the mean of duplicates samples with an error difference less than $5 \%$ 
which is the main impurity in this substrate [19]. Despite the higher initial COD content in crude glycerol in relation to BWW, the higher COD removal achieved for the former substrate could be due to its lower toxicity.

EPS production by $P$. aeruginosa LVD-10 and Enterobacter $\mathrm{sp}$. SW was evaluated using DWW, BWW and crude glycerol as substrates (Fig. 2). The total EPS were extracted and measured as LB- and TB-EPS and their concentrations were based on the dry weight of the extract. Despite that DWW contained a low carbon content and limited nutrients, EPS production was observed. The dry weight concentration of total EPS using DWW were around 96 and $80 \mathrm{mg} / \mathrm{L}$ by $P$. aeruginosa LVD-10 and Enterobacter sp. $\mathrm{SW}$, respectively, whereas in BWW, dry weight concentrations were about 11 times higher than in DWW (Fig. 2). This could be due to the higher available carbon content

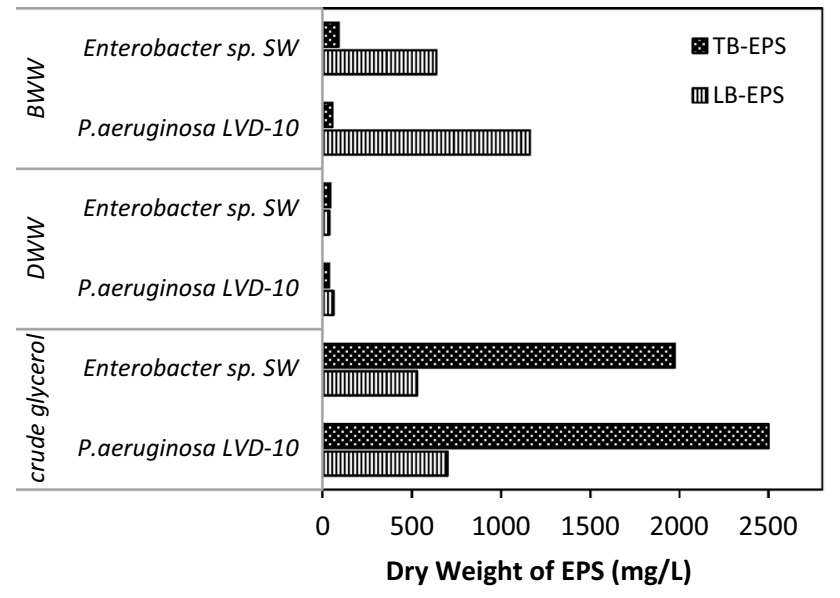

Fig. 2 LB- and TB-EPS production by $P$. aeruginosa LVD-10 and Enterobacter sp. SW at the end of $48 \mathrm{~h}$ of incubation. BWW, DWW and crude glycerol $(4.5 \% v / v)$ were used as substrates for EPS production. The extracted EPS was measured according to its dry weight. Values are the mean of duplicates samples with an error difference less than $7 \%$ in BWW compared to DWW. However, when crude glycerol was used as a substrate, the EPS production was even higher in comparison with the other tested substrates. $P$. aeruginosa LVD-10 and Enterobacter sp. SW achieved a maximum EPS production of 3200 and $2500 \mathrm{mg} / \mathrm{L}$ using crude glycerol as substrate.

In addition, the levels of TB-EPS and LB-EPS produced seemed to depend on the type of wastewater used as substrate. In this study, preferential production of LB-EPS by both tested strains was observed in BWW while with crude glycerol, the TB-EPS content was remarkably higher in proportion and total concentration (Fig. 2). According to Sheng et al. [20], bacteria produce more EPS under unfavorable conditions. Both strains produced higher amounts of LB-EPS using BWW, probably as a strategy of defence against the harsh conditions when incubated in this substrate. LB-EPS are loosely attached to the cell surface, forming a protective barrier that prevents cells to directly contact with the toxic compounds present in BWW. In a previous study conducted by Hou et al. [21] it was found that LB-EPS play a major role in the protective strategy of microorganisms in solution against the effects of heavy metals. In addition, the higher LB-EPS content produced could also be involved in the solubilisation of the hydrocarbons present in BWW. This is in line with the emulsification index where it was observed that the EPS generated by both strains when exposed to BWW had significantly higher emulsification index than that generated using crude glycerol.

\section{Emulsification Activity of EPS}

Emulsification activity is a desired characteristic of EPS for industrial applications, which usually depends on type of substrate, applied conditions and microorganisms. Figure 3 shows the emulsive index of the extracted LB-EPS produced during cultivation of the selected bacteria in BWW
Fig. 3 Emulsification index of the produced LB-EPS by Enterobacter sp. SW (grey bars) and $P$. aeruginosa LVD10 (black bars) using crude glycerol (a) and BWW (b) as substrate. The emulsification index represents the emulsification activity of LB-EPS in olive oil. The EPS dosage for all the tests was $0.5 \% \mathrm{v} / \mathrm{v}$
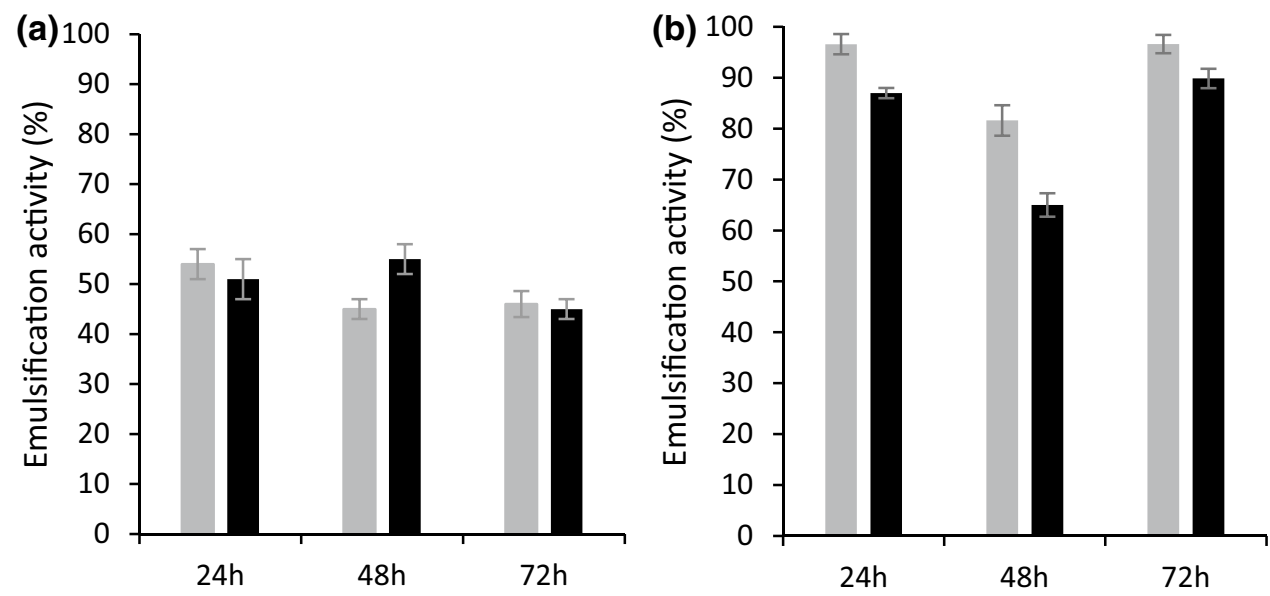
and crude glycerol. The LB-EPS produced in DWW did not show any emulsion formation between the two phases (data not shown). Furthermore, no emulsification activity was observed for the TB-EPS produced in each type of wastewater (data not shown). Nevertheless, a high emulsification activity was observed when the extracted LBEPS interacted with olive oil as an organic phase (Fig. 3), whereas with diesel it did not show any relevant interaction with the EPS (data not shown). Previous studies point out that the protein content of biopolymers plays an important role in its emulsifying capacity, revealing that EPS composed of higher protein fractions can emulsify several hydrophobic substrates [22]. However, in the present study, the protein and carbohydrate content of each type of EPS was not assessed and thus it was not possible to establish a correlation between the protein fraction and the emulsification capability of the extracted LB-EPS. Moreover, to date, most of the studies evaluate the emulsification activity of the total EPS extracted, not revealing the contribution of each type of EPS (LB and TB-EPS) for this property.

The highest EPS emulsification activity was obtained for the LB-EPS produced when both strains were cultivated in BWW at $72 \mathrm{~h}$. The LB-EPS produced in BWW by Enterobacter $\mathrm{sp}$. SW had an emulsive index of $96.6 \%$ and that produced by $P$. aeruginosa LVD-10 had a slightly lower emulsive index of $89.9 \%$ (Fig. 3b). Ramasamy et al. [10] using real petroleum wastewater as substrate, produced EPS with $60 \%$ of emulsification activity (Table 1). Although BWW is composed of several petroleum compounds, the wastewater composition varies and consequently affects the EPS production, composition and characteristics.

\section{Flocculation Activity of EPS}

Another desired characteristic of EPS for industrial applications is the flocculation activity. The highest flocculation activity was obtained for the EPS produced during cultivation of both bacteria in crude glycerol (Fig. 4a). TB-EPS produced by $P$. aeruginosa LVD-10 had a flocculation activity of $81.6 \%$, after the first $24 \mathrm{~h}$ of cultivation in crude glycerol, whereas that produced by Enterobacter sp. SW in the same substrate had a slightly lower flocculation activity of $73 \%$ (Fig. 4a). The flocculation activities of the TB-EPS generated in BWW were lower than $50 \%$ for both strains. With this type of wastewater, the highest flocculation activity was found for Enterobacter sp. SW at the end of $24 \mathrm{~h}$ (Fig. 4b). Similar results regarding the flocculation activity were reported by Nurul Adela et al. [5] when Bacillus marisflavi NA was cultivated in palm oil effluent, producing EPS with a flocculation activity of $80 \%$ (Table 1). To our knowledge, the highest EPS flocculation activity reported in literature was of $95.7 \%$ for Klebsiella mobilis when cultivated in dairy wastewater [8] (Table 1). Moreover, it is important to notice that for both tested substrates, the EPS flocculation activity decreased over time probably as a result of the changes in the EPS composition.

Furthermore, it should be noted that contrary to that observed for the emulsification activity, the flocculation activity was observed for TB-EPS (Fig. 4) but not for LB-EPS (data not shown). However, Bezawada et al. [6] observed similar flocculation activity in TB-EPS (76.4\%) and LB-EPS (67.8\%). Several studies have shown that produced EPS have different properties. Calvo et al. [9] showed that the EPS produced by Ochrobactrum anthropic AD2 using as substrate wastewater containing various hydrocarbons, had an emulsifying activity that varied between $8-95 \%$, but no flocculation activity was detected. On the other hand, Wang et al. [8] reported the production of EPS with a flocculation activity of $95 \%$ when dairy wastewater was used (Table 1) but no emulsification activity was observed for the produced EPS. In this study, Pseudomonas aeruginosa LVD-10 showed to have a great potential for EPS production with the capability of both high emulsification and flocculation activity, depending on the type of wastewater used as substrate. It is important to highlight that few studies have been carried out on EPS production using low-cost substrates, especially wastewater. Enterobacter sp. SW and Pseudomonas aeruginosa LVD-10 are
Fig. 4 Flocculation activity of the TB-EPS produced by Enterobacter sp. SW (grey bars) and $P$. aeruginosa LVD-10 (black bars) in crude glycerol (a) and in BWW (b). Samples were taken at 24,48 and $72 \mathrm{~h}$ of incubation. The EPS dosage for all the tests was $0.5 \% \mathrm{v} / \mathrm{v}$
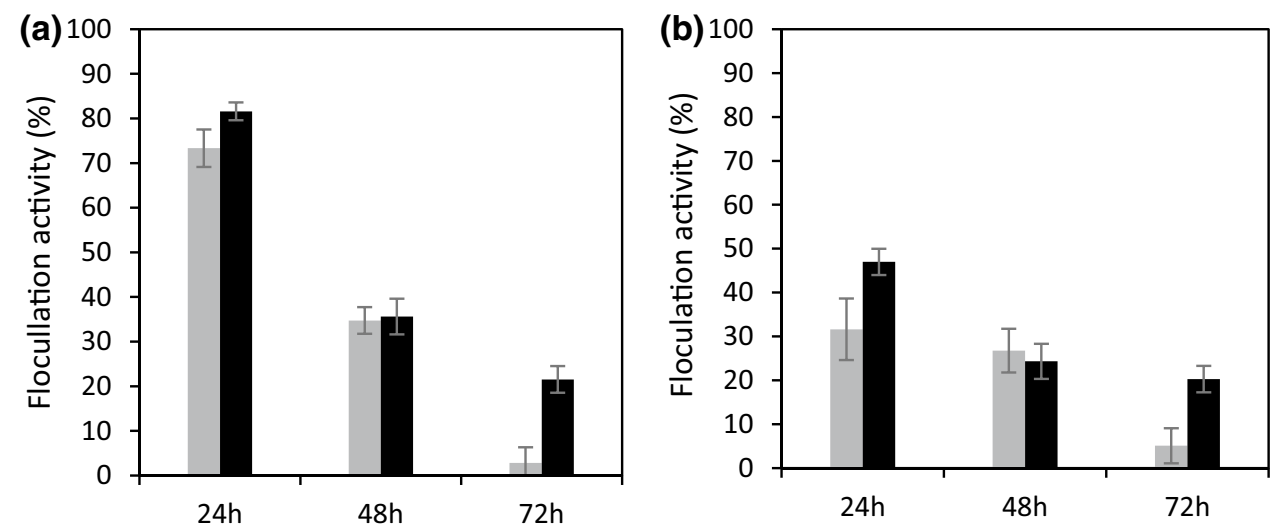
potential candidates for the synthesis of biomaterials such as EPS using waste carbon sources as substrates. However, further studies are needed to scale up the process.

The findings of this study highlight that low-cost substrates can be transformed into EPS with high emulsification and flocculation activity. Wastewater containing heterogeneous mixtures of organic compounds, after being filtered (microfiltration) to remove solids and other microorganisms, can be further used as carbon source for the bacterial production of EPS. The EPS produced can be directly applied in the treatment of wastewater as coagulant/flocculant in the steps of primary settling or clarification. Apart from this, EPS can be used as an emulsifier to enhance oil recovery or oil bioremediation. The above processes operate in non-sterile environments and require high amount of EPS with good emulsification and flocculation activity. Therefore, the required EPS do not have to be highly pure and this will reduce the necessary downstream processing, that will be relatively low compared to other processes that require highly pure EPS.

According to Gupta and Thakur [7], the use of cheap carbon and nutrient sources for large scale EPS production can help raise the benefit-cost ratio thus making the product marketable. Therefore, the main challenges in these processes are the production of high yields of EPS by bacteria and the use of a low carbon source as a substrate.

\section{Conclusion}

Enterobacter sp. SW and Pseudomonas aeruginosa LVD10 showed to be able to simultaneously break down chemicals present in waste streams and to valorise these wastes by the production of EPS biopolymers. The strains were able to efficiently remove COD from DWW, BWW and crude glycerol. For DWW, COD removal efficiencies above 96\% were achieved but for BWW and crude glycerol, which have in their composition recalcitrant compounds, lower COD removals ranging from 51 to $82 \%$ were attained. Interestingly, the EPS production using these recalcitrant wastewaters was considerably higher (a maximum of $3200 \mathrm{mg} / \mathrm{L}$ of EPS by $P$. aeruginosa LVD-10 in crude glycerol) than that with BWW (ca. $100 \mathrm{mg} / \mathrm{L}$ of EPS). Although recalcitrant compounds could inhibit the bacterial metabolism lowering COD removal, they could also trigger a defence response and enhance EPS biosynthesis.

The produced EPS from both strains showed different emulsification and flocculation activities depending on the type of substrate used. EPS with the highest emulsification activity (ca. 96.6 and $89.9 \%$ for Enterobacter sp. SW and $P$. aeruginosa LVD-10) was produced during cultivation in BWW whereas in crude glycerol a maximum of $55 \%$ of emulsification activity was achieved. EPS with a maximum flocculation activity of 81.6 and $73.3 \%$ was produced by LVD-10 and SW using crude glycerol. In addition, LB and TB-EPS produced in the selected substrates had also different behaviour since LB-EPS showed to have emulsification activity but no flocculation activity, whereas for TB-EPS the opposite was observed.

Bacteria able to produce EPS using waste streams along with contaminant removal highlights the possibility of more sustainable and economically competitive processes for biopolymers production.

Acknowledgements E:F. Drakou thanks to COST Action ES1202: Conceiving Wastewater Treatment in 2020 - Energetic, environmental and economic challenges for her Short Term Scientific Mission grant (Ref. COST-STSM-ES1202-21375). C.L. Amorim wishes to acknowledge a research grant from Fundação para a Ciência e Tecnologia (FCT), Portugal (Ref. SFRH/BPD/96481/2013) and Fundo Social Europeu (Programa Operacional Potencial Humano (POPH), Quadro de Referência Estratégico Nacional (QREN)). This work was supported by FCT through project UID/Multi/04423/2013.

\section{Compliance with Ethical Standards}

Conflict of interest The authors declare no conflict of interest.

\section{References}

1. More, T.T., J.S.S. Yadav, Yan, S., Tyagi, R.D., Surampalli, R.Y.: Extracellular polymeric substances of bacteria and their potential environmental applications. J. Environ. Manag. 144, 1-25 (2014). doi:10.1016/j.jenvman.2014.05.010

2. Donot, F., Fontana, A., Baccou, J.C., Schorr-Galindo, S.: Microbial exopolysaccharides: main examples of synthesis, excretion, genetics and extraction. Carbohydr. Polym. 87, 951-962 (2012). doi:10.1016/j.carbpol.2011.08.083

3. Ates, O.: Systems biology of microbial exopolysaccharides production. Front. Bioeng. Biotechnol. 3, 1-16 (2015). doi:10.3389/ fbioe. 2015.00200

4. Madhuri, K. V., Prabhakar, K.V.: Microbial exopolysaccharides: biosynthesis and potential applications. Orient. J. Chem. 30, 1404-1410 (2014). doi:10.13005/ojc/300362

5. Nurul-Adela, B., Nasrin, A.-B., Loh, S.-K.: Palm oil mill effluent as a low-cost substrate for bioflocculant production by Bacillus marisflavi NA8. Bioresour. Bioprocess. 3, 1-8 (2016). doi:10.1186/s40643-016-0096-6

6. Bezawada, J., Hoang, N. V., More, T.T., Yan, S., Tyagi, N., Tyagi, R.D., Surampalli, R.Y.: Production of extracellular polymeric substances (EPS) by Serratia sp.1 using wastewater sludge as raw material and flocculation activity of the EPS produced. J. Environ. Manag. 128, 83-91 (2013). doi:10.1016/j. jenvman.2013.04.039

7. Gupta, A., Thakur, I.S.: Study of optimization of wastewater contaminant removal along with extracellular polymeric substances (EPS) production by a thermotolerant Bacillus sp. ISTVK1 isolated from heat shocked sewage sludge. Bioresour. Technol. 213, 21-30 (2015). doi:10.1016/j.biortech.2016.02.040

8. Wang, S.-G., Gong, W.-X., Liu, X.-W., Tian, L., Yue, Q.-Y., Gao, B.-Y.: Production of a novel bioflocculant by culture of Klebsiella mobilis using dairy wastewater. Biochem. Eng. J. 36, 81-86 (2007). doi:10.1016/j.bej.2007.02.003 
9. Calvo, C., Silva-Castro, G.A., Uad, I., García-Fandiño, C., Laguna, J., González-López, J.: Efficiency of the EPS emulsifier produced by Ochrobactrum anthropi in different hydrocarbon bioremediation assays. J. Ind. Microbiol. Biotechnol. 35, 14931501 (2008). doi:10.1007/s10295-008-0451-5

10. Ramasamy, S., Mathiyalagan, P., Chandran, P.: Characterization and optimization of EPS-producing and diesel oil-degrading Ochrobactrum anthropi MP3 isolated from refinery wastewater. Pet. Sci. 11, 439-445 (2014). doi:10.1007/s12182-014-0359-9

11. Drakou, E., Koutinas, M., Pantelides, I., Tsolakidou, M., Vyrides, I.: Insights into the metabolic basis of the halotolerant Pseudomonas aeruginosa strain LVD-10 during toluene biodegradation. Int. Biodeterior. Biodegrad. 99, 85-94 (2015). doi:10.1016/j.ibiod.2014.10.012

12. Oliveira, R., Melo, L., Oliveira, A., Salgueiro, R.: Polysaccharide production and biofilm formation by Pseudomonas fluorescens: effects of $\mathrm{pH}$ and surface material. Colloids Surf. B. 2, 41-46 (1994). doi:10.1016/0927-7765(94)80016-2

13. Sivan, A., Szanto, M., Pavlov, V.: Biofilm development of the polyethylene-degrading bacterium Rhodococcus ruber. Appl. Microbiol. Biotechnol. 72, 346-352 (2006). doi:10.1007/ s00253-005-0259-4

14. Bala Subramanian, S., Yan, S., Tyagi, R.D., Surampalli, R.Y.: Extracellular polymeric substances (EPS) producing bacterial strains of municipal wastewater sludge: isolation, molecular identification, EPS characterization and performance for sludge settling and dewatering. Water Res. 44, 2253-2266 (2010). doi:10.1016/j.watres.2009.12.046

15. Nievas, M.L., Commendatore, M.G., Olivera, N.L., Esteves, J.L., Bucalá, V.: Biodegradation of bilge waste from Patagonia with an indigenous microbial community. Bioresour. Technol. 97, 2280-2290 (2006). doi:10.1016/j.biortech.2005.10.042

16. APHA: Standard Methods for the Examination of Water and Wastewater, p. 541. APHA, Wasihgton, DC (1999)

17. Cooper, D.G., Goldenberg, B.G.: Surface-active agents from two Bacilllus species. Appl. Environ. Microbiol. 53, 224-229 (1987)

18. Sathiyanarayanan, G., Kiran, G.S., Selvin, J.: Synthesis of silver nanoparticles by polysaccharide bioflocculant produced from marine Bacillus subtilis MSBN17. Colloids Surf. B. 102, 13-20 (2013). doi:10.1016/j.colsurfb.2012.07.032

19. Viana, M.B., Freitas, A. V., Leitão, R.C., G.A.S. Pinto, Santaella, S.T., Freitas, A. V., Leitão, R.C., G.A.S. Pinto, Santaella, S.T.: Anaerobic digestion of crude glycerol: a review. Environ. Technol. Rev. 1, 81-92 (2012). doi:10.1080/09593330.2012.692 723

20. Sheng, G.-P., Yu, H.-Q., Li, X.-Y.: Extracellular polymeric substances (EPS) of microbial aggregates in biological wastewater treatment systems: a review. Biotechnol. Adv. 28, 882-894 (2010). doi:10.1016/j.biotechadv.2010.08.001

21. Hou, W., Ma, Z., Sun, L., Han, M., Lu, J., Li, Z., Mohamad, O.A., Wei, G.: Extracellular polymeric substances from coppertolerance Sinorhizobium meliloti immobilize $\mathrm{Cu}^{2+}$. J. Hazard. Mater. 261, 614-620 (2013). doi:10.1016/j.jhazmat.2013.06.043

22. Llamas, I., Amjres, H., Mata, J.A., Quesada, E., Béjar, V.: The potential biotechnological applications of the exopolysaccharide produced by the halophilic bacterium Halomonas almeriensis. Molecules. 17, 7103-7120 (2012). doi:10.3390/ molecules 17067103 